\title{
ARTE FIGURATIVA DE TAUBATÉ (SP) TRÊS PERCURSOS DO TORNAR-SE FIGUREIRO
}

Valéria Aquino (Uerj)

Com o objetivo de refletir sobre o processo de ensino $e$ aprendizagem da arte figurativa em Taubaté (SP), este artigo aborda três diferentes formas de aprendizagem, a partir das diferentes categorias classificatórias nativas: figureiros de família, figureiros tradicionais e novos figureiros. Dessas categorias, apesar de distintas, emerge a própria concepção do que é ser figureiro em Taubaté.

ARTE FIGURATIVA; TAUBATÉ; FIGUREIROS; ARTE POPULAR.

AQUINO, Valéria. Arte figurativa de Taubaté (SP): três percursos do tornar-se figureiro. Textos escoIhidos de cultura e arte populares, Rio de Janeiro, v.10, n.1, p. 41-62, mai. 2013. 


\section{FIGURATIVE ART OF TAUBATÉ (SP)}

THREE ROUTES TO BECOMING A FIGURE MAKER

Valéria Aquino (Uerj)

Aiming at the reflection on the teaching and learning of figurative art in Taubate (SP), this article discusses three different forms of learning, from the different native classification categories: family figure makers, traditional figure makers and new figure makers. From these categories, however distinct, emerges the conception of what being a figure maker in Taubaté means.

FIGURATIVE ART; TAUBATÉ; FIGURE MAKERS; FOLK ART.

AQUINO, Valéria. Arte figurativa de Taubaté (SP):

três percursos do tornar-se figureiro. Textos escoIhidos de cultura e arte populares, Rio de Janeiro, v.10, n.1, p. 41-62, mai. 2013. 


\section{UM POUCO DA HISTÓRIA DA PRODUÇÃO FIGURATIVA}

Localizada no Vale do Paraíba, a 301 quilômetros do Rio de Janeiro e 134 de São Paulo, e às margens da Rodovia Presidente Dutra (BR-116), a cidade de Taubaté, assim como outras da região (Tremembé, São José dos Campos, Pindamonhangaba), possui representativa produção artesanal.

Tendo o barro como principal matéria-prima, as peças produzidas pelos denominados figureiros de Taubaté apresentam cores vivas, em especial o azulultramar. Os figureiros se veem e são vistos como os únicos no Brasil a utilizar essa tonalidade de azul, que pode mesmo ser considerada um símbolo diacrítico dessa produção no contexto do artesanato brasileiro.

A produção figurativa de Taubaté vem, desde meados do século XX, sendo associada ao bairro Imaculada Conceição e principalmente à rua de mesmo nome, que é ainda hoje um dos principais pontos de referência dessa produção. Tal associação se deve ao fato de a maioria dos figureiros ter ali habitado por muito tempo, e muitos ainda morarem nessa rua, a principal do bairro. Atualmente, a maior parte dos cerca de 50 figureiros, com idades que variam de 10 a 81 anos, está organizada na Associação Maria da Conceição Frutuoso Barbosa, também conhecida como Casa do Figureiro e localizada no próprio bairro.

Seus relatos apontam para uma tradição de mais de 150 anos de arte figurativa no bairro e destacam sua origem associada à prática de armar presépios natalinos, que seria um hábito secular na cidade.

A bibliografia existente a respeito da produção artesanal de Taubaté parece corroborar essa visão. Para Abreu (1980, p. 27), seria a partir da prática cristã de armar presépios que a cerâmica figurativa, desenvolvida principalmente por pessoas das camadas populares, se instaura em Taubaté. "Muitas famílias, com menos posse ou mais habilidade manual e gosto artístico, faziam suas figurinhas de madeira ou barro, fato que também se foi tornando tradição na cidade" (grifo da autora).

O nome da Associação - Maria da Conceição Frutuoso Barbosa - faz referência à artesã que, de acordo com relatos colhidos entre os figureiros e pesquisas já realizadas (FLORES, 1987; MACHADO, 2003; OLIVEIRA, 2007), deu início ao trabalho com barro na região do que é hoje o bairro Imaculada.

A história de Conceição Frutuoso Barbosa é, para muitos figureiros, uma espécie de mito de origem da produção artesanal no bairro. Sempre que eu perguntava sobre os primeiros figureiros do local ouvia como resposta Conceição Frutuoso, homenageada com a atribuição de seu nome à Casa do Figureiro. 


\section{FAZENDO “FIGURINHAS"}

Quando se pergunta hoje aos figureiros de onde vem essa denominação, todos são muito enfáticos em dizer que esse nome se relaciona à produção de figuras para presépios e que "antes" alguns artesãos faziam apenas as "figurinhas" do presépio. Esse tempo antigo a que se referem os artesãos diz respeito ao início do século XX, época em que se localiza a mais remota lembrança que emerge de seus relatos.

Por figurinhas, eles designam todas as peças que compõem o presépio com exceção daquelas com traços humanos, como a sagrada família, os reis magos e os anjos, consideradas peças sacras, ou seja, trata-se das representações de animais, entendidas por eles como secundárias.

Em um primeiro momento, figureiro, enquanto categoria nativa de classificação ${ }^{1}$ que designa os produtores de peças zoomorfas para presépio, parece emergir nas falas como algo que tem sua origem a partir de uma relação de oposição e inferioridade com a categoria santeiro, que designa, segundo seu entendimento, aqueles que produzem as figuras humanas, especificamente as peças sacras.

Depois que se tornou "figureiros". Porque antes a turma aqui da Imaculada era chamada como santeiro, porque arrumava santo, fazia os santos, entendeu?! Aí tinha aquelas pessoas que não conseguiam fazer o santinho, tinha que fazer o rosto, o olho, o nariz, era mais difícil, o cabelo, a mão. Achava mais difícil. Aí eles começaram a fazer o burro, a vaca, o carneiro, aí que se tornou... Uns fazem as figuras de gente, de santo, e fulano faz os bichinhos, faz as figurinhas, que são as figurinhas do presépio. Aí veio, figurinha, figurinha, ficou os "figureiros de Taubaté".

Valéria: Mas figureiro também faz santo, não é?

Arlete: Faz também, mas daí não chama mais de santeiro, chama de figureiro. Agora é só figureiro (Arlete Sampaio, 2009).

É possível perceber nas falas nativas - como nessa de Arlete Sampaio, em entrevista à autora - que buscam nas explicações sobre a origem do termo figureiro, uma relação hierárquica de onde emergiu a própria categoria. Ao que parece, a diferenciação entre as duas categorias tinha como referência a maior ou menor habilidade na confecção das peças humanas. Na visão de alguns artesãos, os santeiros eram aqueles que possuíam mais destreza e por isso estavam mais aptos a produzir os santos, enquanto os figureiros eram todos aqueles que, não conseguindo produzir as representações humanas, acabaram por se especializar 
na produção das figuras zoomorfas, os animais entendidos como "figurinhas" do presépio.

Essa visão, no entanto, se refere a um tempo passado, e é utilizada apenas para explicar a origem do termo figureiro. Atualmente todos devem necessariamente saber fazer tanto as figuras de animais quanto as humanas. Apesar disso, há que ressaltar o que podemos considerar resquícios de uma hierarquia, visto que o processo de aprendizado é dividido informalmente em duas etapas, que consistem em aprender a modelar figuras de animais e só a partir do domínio dessa técnica passar ao aprendizado da modelagem de figuras humanas, pois é consenso entre eles que a confecção destas últimas requer mais domínio das técnicas de modelagem.

Pode-se dizer que a categoria figureiro possui dois níveis de significado: no que se associa a explicações relativas à origem do termo, a categoria denota menos habilidade, de maneira que aqueles considerados figureiros fossem percebidos como pouco capacitados na confecção de figuras humanas. Nesse nível de significação, a categoria emerge de uma relação hierárquica, a partir da ideia de habilidade, talento, e ocupa lugar inferior em relação à categoria santeiro.

Por outro lado, ao focalizarmos seu uso e significado contemporâneos, a categoria figureiro emerge como englobadora da categoria santeiro. Como relatou Arlete Sampaio, atualmente os artesãos também fazem santos, não sendo, entretanto, mais denominados santeiros, mas apenas figureiros.

Nesse nível de significação, enquanto o santeiro se manteve restrito à produção de peças sacras, com base na habilidade para a representação de figuras humanas, o figureiro, além das figuras zoomorfas, passou a produzir peças sacras e outras figuras humana, tornando-se uma categoria englobadora da categoria santeiro. Dessa forma, a categoria figureiro passou a se referir às figuras em geral, aos animais, aos santos e a outras representações de figuras humanas.

Enquanto no primeiro nível de significação a categoria figureiro se refere à habilidade na confecção de determinada peça, no segundo nível ela reporta à ampliação do repertório de peças modeladas, que pode ser compreendido a partir do domínio das técnicas, ou desenvolvimento da habilidade, que permitiu a confecção das figuras humanas.

\section{A "DESCOBERTA" DOS FIGUREIROS}

Nas várias conversas informais que tive com a figureira Luiza Santos, a mais velha ainda em atividade, em que ela falava sobre a trajetória da produção figurativa na Rua Imaculada, ficou bastante clara a existência de acontecimentos, personagens e lugares que marcaram a memória do grupo. 
Em A memória coletiva Maurice Halbwachs (1990) estabelece que os indivíduos não recordam sozinhos; eles precisam da memória de outras pessoas para configurar suas próprias recordações. Para lembrar, os indivíduos precisam da memória coletiva, ou seja, da memória que foi construída a partir da interação com outros indivíduos.

Myriam Lins de Barros (1989, p. 31), dialogando diretamente com as formulações de Halbwachs, destaca que a "memória individual é um ponto de vista da memória coletiva, e esse ponto de vista varia de acordo com o lugar social que é ocupado; este lugar, por sua vez, muda em função das relações que se tem com outros meios sociais".

Levando em conta todas as especificidades que devem ser consideradas ao abordar discursos que remetem a uma memória individual ou coletiva, gostaria de evidenciar alguns acontecimentos e personagens destacados por Luiza Santos. Por ser a figureira mais velha e por ter participado ativamente de vários momentos tidos como significativos na produção figurativa, pode-se dizer que Luiza se reconhece e é reconhecida como guardiã da memória dos figureiros, como alguém que realiza mediação entre gerações quando transmite a história de um passado vivido e experimentado (BARROS, 1989).

De acordo com Luiza, foi a partir da década de 1940 que os figureiros começaram a ganhar mais visibilidade por meio do contato com o historiador e folclorista de São Paulo Rossini Tavares de Lima.

Rossini Tavares, que fazia parte do Movimento Folclórico e foi secretáriogeral da Comissão Paulista de Folclore entre 1948 e 1976, ${ }^{2}$ desenvolvia também pesquisas no campo do folclore pelo Centro de Pesquisas Mário de Andrade, que era vinculado ao Conservatório Dramático e Musical de São Paulo, no qual Rossini era professor. As atividades de pesquisas e os trabalhos de campo desenvolvidos pelo Centro deram origem à reunião de objetos que posteriormente resultou na criação do Museu de Artes e Técnicas Populares de São Paulo, em $1961^{3}$ (REIS, 2010, p. 5).

Para Rossini Lima (1972), era preciso entender os fatos folclóricos como dinâmicos, como fenômenos que aconteciam em determinado momento, sendo assim necessário contextualizá-los em seus aspectos sociais. Foi com essa postura e no princípio da construção de um acervo que desse conta de uma representação do perfil nacional a partir do material folclórico - postura condizente com os ideais do Movimento Folclórico - que Rossini, por volta de 1940, se aproximou do trabalho artesanal desenvolvido pelos figureiros de Taubaté. Como relatou Luiza Santos, "ele foi a primeira pessoa que deu uma mão" para os figureiros. 
Foi por intermédio de Rossini que os figureiros começaram a ganhar visibilidade fora da cidade de Taubaté. O primeiro convite para participar de exposições ocorreu em 1954, por ocasião das comemorações do quarto centenário de São Paulo, ainda que só a partir de 1964 eles começassemm a participar efetivamente de exposições e feiras. Essa maior visibilidade atraiu novos compradores para as peças, acarretando também mudanças na produção artesanal. Pode-se dizer que Rossini Tavares é, ainda, um dos principais personagens que permeia a memória coletiva dos figureiros de Taubaté relacionada à ascensão da arte figurativa no bairro.

\section{A AMPLIAÇÃO DO REPERTÓRIO}

Até a "descoberta" dos artesãos de figuras de barro pelos intelectuais ligados ao Movimento Folclórico e a consequente divulgação do trabalho artesanal, a venda das figuras para presépio se restringia ao Mercado Municipal de Taubaté e ocorria durante o período natalino. Embora a produção das figuras pudesse acontecer durante todo o ano, era apenas nos meses que antecediam ao Natal que ela se intensificava. Com o surgimento de um novo público interessado, esse arranjo temporal que orientava a produção começou a tomar outra configuração.

A procura das peças dos figureiros passou a acontecer durante todo o ano, ou seja, já não se concentrava no período das festas natalinas. Essa nova configuração da demanda acarretou mudanças significativas, tanto no que diz respeito ao período de produção, que se estendeu pelo ano todo, quanto ao repertório de peças produzidas, que começam gradativamente a extrapolar o destino anterior, que priorizava a composição de presépios.

Meireles (apud PEREIRA, 1957, p. 98) chama a atenção para a natureza plástica dos presépios, destacando o grande número e variedade de figuras neles encontradas.

Nas capelas dos palácios, e nos inúmeros oratórios, a cena da Natividade teria de encontrar um fervor certo, pela gentileza das figuras e pela expressão do acontecimento. Em sua forma estética, ficará reduzida a um pequeno número de elementos plásticos. Mas as vastas romarias, com a participação do povo, as festas religiosas, com música, dança, foguetório, comes e bebes, ofereciam motivos copiosos para maior desenvolvimento do presépio. Por imensos caminhos, até a manjedoura, houve uma larga invenção profana: soldados, agricultores, pastores, lavadeiras, músicos, mendigos, crianças, artesãos de toda a qualidade, dirigiam-se por esses íngremes caminhos que iam dar à mansão divinizada. Talvez porque a viagem fosse longa, nem todos ficaram em atitude de marcha: alguns sen- 
taram-se a comer, outros a lavar roupa, outros a dar de beber aos cavalos, outros a dormitar à sombra de algumas árvores. E os músicos desataram a tocar sanfonas, rebecas ou violas, e formaram-se rodas de dança, enquanto os bichinhos, naturalmente destinados à oferenda, também se distraíam em redor, os patos pelos lagos, as galinhas, porcos, os carneiros misturados pelos caminhos.

Destaca ainda que as figuras do presépio podem ser retiradas, vindo a desempenhar um fim lúdico ou decorativo, tendo também a possibilidade de atualização e aumento das peças que compõem o presépio.

É Pereira (1957, p. 108) quem chama a atenção para uma estreita relação entre as figuras de presépios e a modelagem popular, que, de acordo com o autor, "é originada num velho costume de se executar estes trabalhos como atividade lúdica, mesmo visando um fim específico". Dessa forma, para o autor, os personagens do presépio teriam dado origem às esculturas ou modelagens, agora com fins decorativos ou lúdicos, destinadas a servir como brinquedos de criança.

Ainda na década de 1950, os presépios de Taubaté chamavam a atenção pela variedade de temas representados. E é justamente essa variedade um dos assuntos da reportagem de Luiz Ernesto, publicada no periódico Tribuna da Imprensa, em 23 de janeiro de 1957, sob o título Tem cobra, onça e raposa nos presépios de Taubaté:

Antônia Maria dos Santos vende cada figurinha a $\mathrm{Cr} \$$ 5,00 (média). As figurinhas têm de tudo: boi, burro, os três Reis Magos (em pé ou a cavalo), cobra, tartaruga, vaca, peru, galinhas e pintinhos e os santos - Nossa Senhora, São José e o Menino Jesus. Nastácia Costa explica que o presépio popular de Taubaté deve ter 31 figuras.

(...) E diz Gentil de Camargo, a grande autoridade (história, tradição e folclore) do Vale do Paraíba:

"A arte das figureiras não está caindo. O que há talvez é uma renovação. Figuras dos feitos de 32, 45 (FEB) ${ }^{4}$ e outros estão 'entrando' para os presepinhos. Vale! (...) E a paisagem se anima - povoada de onças, camelos, soldados de 32, soldados da guerra do Paraguai, ursos, macacos, cobras, galinhas, patos no lago de espelho, os noivos, homens, mulheres, casinhas de papelão, bichos e gente, numa irrealidade geográfica e histórica, onde a imaginação se compraz".

Como Meireles (apud PEREIRA, 1957) destaca, eram inúmeros os temas da modelagem popular que compunham o presépio. A utilização dessas figuras para outros fins - decorativo ou lúdico - pode ser compreendida também como estímulo para constantes renovações e inspirações temáticas. 
Associado à ampliação do repertório de peças produzidas ocorreu também o aperfeiçoamento do trabalho de alguns figureiros do bairro Imaculada. De acordo com Luiza Santos, à medida que foram surgindo novos compradores, exposições e feiras, a produção artesanal foi ficando pequena diante da demanda, o que acabou, de certa forma, estimulando o interesse de alguns figureiros em aperfeiçoar suas técnicas. Aqueles que modelavam apenas figuras de animais ampliaram seu repertório individual, passando a modelar também figuras humanas.

Embora se inaugure um novo período da produção artesanal a partir do contato com Rossini Tavares de Lima, quando os figureiros foram ganhando mais visibilidade, a cerâmica figurativa de Taubaté já não se limitava à produção de presépios simples - constituídos apenas pela sagrada família - como evidencia a reportagem citada.

A variada gama de temas presentes nos presépios, como os soldados da Revolução Constitucionalista ou da Guerra do Paraguai, já mencionados, demonstra que os personagens modelados nem sempre estavam ligados ao repertório religioso, indicando a abertura das temáticas para o contexto secular. Por outro lado, deve-se considerar também que a própria inserção de temas não religiosos no contexto do presépio confere, em alguma medida, sacralidade às peças, sem contudo interferir em um possível uso ordinário das figuras fora do período natalino. Com isso quero apenas chamar a atenção para o fato de que a produção artesanal, embora motivada inicialmente por uma devoção religiosa, se expandiu para outras temáticas a ponto de se tornar autônoma da demanda natalina ou da própria finalidade religiosa.

\section{"UMA CASA PARA OS FIGUREIROS"}

Desde meados da década de 1980, os figureiros da Rua Imaculada demandavam junto à prefeitura a construção de um espaço de uso coletivo para produção e comercialização das figuras. A demanda era encabeçada por Luiza Santos que, por ser conhecida de vários políticos da região, buscava usar suas influências a favor do grupo. Embora os figureiros desejassem possuir um espaço para produção e venda na própria Rua Imaculada, visto que já era forte a associação entre o trabalho artesanal de figuras de barro e a rua, a prefeitura de Taubaté optou por construir o espaço na Rua dos Girassóis, transversal à Imaculada, na qual, alegava, não havia terreno disponível para a construção do espaço adequado.

Construída em 1993, a Casa do Figureiro ocupa ampla área, e sua estrutura física é composta por duas grandes salas. Em uma delas funciona a loja da Casa, onde são expostas as peças para venda. A outra sala é utilizada para produção e armazenamento de peças e matéria-prima. 
Mesmo com a Casa finalizada os figureiros enfrentaram várias dificuldades, entre elas a viabilização de seu funcionamento, o que incluía, além do mobiliário necessário à produção e venda das figuras, a organização dos recursos humanos responsáveis pelo atendimento ao público e realização de limpeza, por exemplo.

Um dos maiores problemas enfrentado pelos figureiros consistia na manutenção da Casa, aberta ao público, disponível a visitações e com constante produção de figuras para a venda. Vale lembrar que até esse momento eles produziam e vendiam em suas próprias casas, tinham relativo controle sobre a quantidade de peças vendidas por mês e possuíam, em sua maioria, clientela fixa que geralmente fazia encomendas com antecedência.

Manter a Casa do Figureiro permanentemente aberta ao público, uma vez que ela era também um ponto comercial, esbarrou em novos obstáculos. O pequeno número de associados (15 em 1993) dificultava a manutenção da Casa sempre aberta, pois para isso era necessário a constante permanência de, no mínimo, dois figureiros trabalhando em horário comercial. Associado a isso, há também o fato de o limitado número de peças produzidas não atender às novas demandas vindas dos clientes surgidos com a criação da Casa do Figureiro.

Houve, então, a necessidade de estimular a entrada de outros figureiros para viabilizar o funcionamento da Casa e garantir a produção artesanal para a nova demanda. Com essa intenção foi criado um curso para "novos figureiros", a "escolinha", como muitas vezes eles referem. Entre 2008 e 2012, período em que se deu meu contato com os figureiros, a expressão novos figureiros era ainda recorrente entre eles para designar aqueles que ingressaram na arte figurativa após a criação da Casa do Figureiro e distingui-los dos chamados figureiros de família ou figureiros tradicionais, isto é, aqueles que pertencem a grupos familiares envolvidos na produção figurativa há, ao menos, duas gerações e/ou que habitavam o bairro Imaculada Conceição. A partir da escolinha surgem as categorias classificatórias entre os figureiros, que toma como critério de distinção a forma com que se deu o processo de ensino e aprendizagem: enquanto para os novos esse processo se deu por meio do ensino formal na escolinha, para os chamados de família e/ou tradicionais se deu no âmbito familiar e informal.

De acordo com Josiane Sampaio, uma das instrutoras do curso, ele visava ensinar os interessados a "fazer umas pecinhas", o que não implicava necessariamente seu ingresso na Associação. Após um ano de curso realizava-se uma reunião com todos os associados e decidia-se, a partir da análise das peças produzidas pelos aprendizes, quem estava apto ou não a integrar a Casa do Figureiro, o que, no entanto, só se concretizava no ano seguinte. Eram necessários, portanto, 
dois anos de vinculação à Casa do Figureiro para que o novo artesão se tornasse membro efetivo da Associação.

Os cursos foram realizados durante três anos, sem que se saiba precisar quantas pessoas deles participaram. Décio de Carvalho, em entrevista à autora em 2009, afirma que a participação foi pequena, de apenas sete pessoas. Apesar dessa iniciativa de criar regras para a entrada de novos figureiros outros teriam entrado para a Casa sem participar dos cursos.

Os outros, que são os atuais novos figureiros não são frutos diretos do curso. Foram amigos de figureiros que faziam algum tipo de atividade de artesanato com barro, e passaram a assumir a característica do trabalho do figureiro em função desse colega ou no convívio na Casa do Figureiro. O caso da Marilisa, por exemplo, ela é parente de um tio meu. Então ela perguntou e eu apresentei à Casa, mas ela já fazia com alguma técnica e alguma característica que se mantém até hoje no trabalho dela. (...) Então com outros figureiros o processo foi um pouco semelhante. Vieram, no caso do Éden, por exemplo, ele já era professor de arte, veio com alguma técnica, mudou, assumiu alguma característica dos figureiros, então houve uma mescla.

Contudo, embora não tendo participado dos cursos, alguns candidatos a figureiros foram aceitos pelos integrantes da Casa mediante a apresentação de algumas peças modeladas.

Atualmente a entrada de novos integrantes não é permitida pela Associação. Embora nem todos os figureiros concordem com essa restrição a maioria acatou a criação de uma cláusula no estatuto da Associação que limita o número de associados a 40 pessoas.

Entre os motivos apresentados pelo grupo para a extinção dos cursos de formação e a estipulação de um número máximo de associados, está a limitação espacial da Casa do Figureiro. Argumenta-se que não há espaço disponível para o trabalho de mais de 40 pessoas considerando, entre outras coisas, a necessidade de armazenamento de matéria-prima e espaço para a própria confecção das peças.

Outro argumento se refere à preocupação em manter equilíbrio entre oferta e demanda de peças. Nesse caso, um número muito grande de figureiros poderia desencadear a desvalorização das peças e, consequentemente, colocar em risco a sobrevivência daqueles que vivem apenas da produção figurativa.

É interessante destacar nos discursos sobre a extinção dos cursos o fato de que o argumento inicialmente utilizado para justificar sua própria existência, 
ou seja, a possibilidade de aumentar a produção, levando em conta o aumento da procura, passa, posteriormente, a ser usado para justificar sua extinção. Nesses termos, a extinção dos cursos se deu justamente quando os figureiros alcançaram equilíbrio entre a oferta e a demanda das peças.

Dessa forma, mesmo a entrada de um figureiro vindo de uma família classificada como tradicional iria esbarrar na problemática da exiguidade de espaço, já que o trabalho requer mesas, forno e armários para armazenar peças e matéria-prima. Atualmente as falas mais correntes afirmam que é vetada a entrada de qualquer figureiro, caso não haja vacância de associados.

No entanto, na prática essas "regras" parecem ser negociadas. Houve o caso, por exemplo, de uma figureira que se desvinculou da Associação por ter sido empregada em função que não Ihe permitia a conciliação com o trabalho da Casa do Figureiro, mas, após sair desse emprego, retornou à Associação, apesar da suposta inexistência de vagas. Essa exceção foi explicada tomando como justificativa o fato de essa figureira ser, acima de tudo, membro de uma família tradicionalmente conhecida no bairro como vinculada à produção artesanal figurativa. Acrescenta-se ainda que a preocupação principal da Associação é que não entre "qualquer pessoa", explicitando que qualquer pessoa se refere àqueles sem vínculo familiar com a modelagem de barro.

Tais contradições levam a crer que há uma tentativa, por parte de alguns, de manter determinada hegemonia entre os figureiros já associados. Essa hegemonia pode ser caracterizada em dois níveis, dizendo respeito um às famílias tradicionais que fazem parte da Casa do Figureiro e controlam a entrada de novos integrantes a partir dos privilégios dados a seus familiares, o outro ao posicionamento da própria Associação enquanto grupo que, utilizando alegações como a falta de espaço e ampliação da concorrência interna, caso aceite novos membros, acaba, de alguma forma, construindo certa hegemonia da produção figurativa.

Podemos, portanto, afirmar que a Casa do Figureiro concentra a produção figurativa de Taubaté e domina a transmissão das técnicas artesanais, sendo o centro articulador da legitimação dos artesãos como figureiros.

\section{TRÊS PERCURSOS DO TORNAR-SE FIGUREIRO}

As diferentes categorias classificatórias, surgidas com a criação da Casa do Figureiro, explicitam também diferentes trajetórias no processo de construção do artesão enquanto figureiro. Passo agora a relatar brevemente o percurso de três artesãos quanto à formação e ao processo de legitimação como figureiro. 


\section{Arlete Sampaio - o barro está no sangue}

Arlete Sampaio faz parte da terceira geração de figureiros da família Sampaio, que é atualmente uma das maiores famílias de figureiros de Taubaté - até final de 2010, 11 membros trabalhavam ativamente na produção artesanal.

Ao relatar o processo de aprendizagem em sua família, Arlete explicita o caráter lúdico da lida com o barro experimentado na infância. Em conversa informal, contou-me que seus primeiros e principais brinquedos eram feitos de barro, que aos sete anos já modelava algumas figuras, que sua mãe, a figureira Anita Sampaio, muitas vezes dava o barro para ela e suas irmãs "brincarem", e que de observar sua mãe fazendo figuras começou a imitá-la, produzindo ela própria seus brinquedos.

Em entrevista à autora, em 2009, Micheli Sampaio, filha de Arlete, pertence à quarta geração de figureiros da família, também conta que aprendeu no dia a dia, "eu via todos os dias e por isso já estava no sangue aquilo".

O que chama a atenção tanto no relato de Micheli quanto no de Arlete é a naturalização do processo de aprendizagem, o que denota o caráter não consciente da aquisição dos conhecimentos e habilidades, ou seja, das competências relativas à modelagem figurativa.

Em todas as chamadas famílias tradicionais é possível encontrar relatos muito semelhantes a esses. O que parece caracterizar o processo de ensino/ aprendizagem dentro de uma família de figureiros é o aspecto de convivência cotidiana com os processos de produção artesanal, o que colabora para que o ensinar e o aprender se deem de forma inconsciente.

Para muitos figureiros tradicionais, principalmente para aqueles que começaram sua produção artesanal antes da criação da Casa do Figureiro, os ensinamentos da lida com o barro não se limitam à transmissão de técnicas de modelagem, mas abrangem desde o processo de extração do barro ao acabamento das peças. Nos relatos de alguns figureiros de família evidencia-se o fato de que esses ensinamentos eram transmitidos no dia a dia dos figureiros e de sua vizinhança na Rua Imaculada.

Olha, o que eu lembro é que minha mãe falava assim: "Amanhã a gente vai buscar argila". A gente ficava superfeliz. Por quê? Porque lá era onde a gente enfrentava os matos, os espinhos, boi, vaca. Passava em lugar difícil até chegar no rio. Só que a gente, nessa época, reunia uma turminha que ia a mãe e os filhos, e filho homem. Os moleques eram mais espertos para andar no meio do mato, nos ajudavam, e a gente se divertia muito porque a gente tomava banho no rio, entendeu?! E chegava lá cavucava, e pegava um 


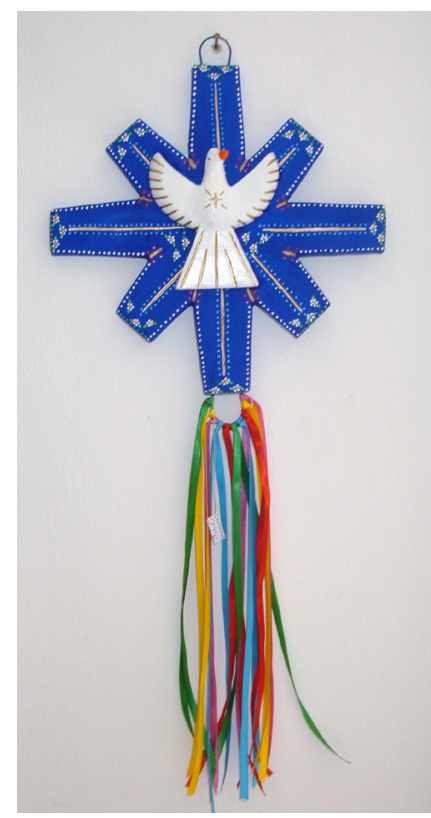

\section{Figura 1: Divino ' $X$ ' Cruz de Arlete Sampaio Foto da autora}

pedacinho de argila e levava lá no barranco para minha mãe, no caso, para ver se a argila estava boa. Aí minha mãe falava: "Ah, está com muita areia". Daí, cavucava em outro lugar, "Ah, está com muito fiapo de mato". Tinha raiz e mato embaixo, estava muito ruim. Até que achava um lugar que estava bom. Aí, ela tirava a argila, ia pegando os pedaços, colocando dentro do saco de arroz, que é um saco mais grosso, conservava mais. Aí a gente fazia aquele monte de saco de arroz, enchia tudo de argila. Daí, ia subindo o barranco, aí subia o barranco e vinha tudo sujo, vinha molhado. Só que quando estava vindo: "Ai mãe, não aguento carregar". Ela falava: "Ah, deixa um pedaço aí". A gente escondia os pedaços no meio do mato, sabe. Uns pacotinhos verdes no meio do mato. E vinha embora. No outro dia a gente ia buscar. Assim que a gente fazia. E quando chegava em casa, tinha trabalho, porque a gente amassava a argila na mão, pedacinho por pedacinho, procurando pedrinha. Pedrinha, mato mesmo, separando, deixando no ponto para a gente trabalhar. Era bem mais difícil (Arlete Sampaio, 2009).

Neste trecho Arlete destaca o processo de extração do barro que era realizado no Rio Itaim, nas imadiações da Rua Imaculada, chamando a atenção para o caráter lúdico dessa investida experimentada em sua infância.

O caminho até o rio já era por si só uma grande aventura, pois "era onde a gente enfrentava os matos, os espinhos, boi, vaca. Passava em lugar difícil". Além de compartilhar a aventura com uma "turminha" havia também a recompensa que era poder tomar banho no rio. Toda essa diversão com caráter de aventura pode ser compreendida como uma maneira de introduzir os ensinamentos da lida com o barro, por exemplo, na descrição da escolha da argila adequada, posto que as crianças mostram os vários tipos de argila encontrados ao adulto presente, que então seleciona o mais adequado ao trabalho, aprendendo, assim, os critérios que delimitam a escolha do barro de qualidade: pouca areia, sem fiapos de raízes etc. 
O processo de aprendizado de Arlete Sampaio condensa características compartilhadas por todos os figureiros de família, podendo ser entendido como caso representativo da maneira com que se dá o ensino e aprendizado nessa categoria classificatória (Figura 1).

\section{Décio de Carvalho - um figureiro tradicional}

Décio de Carvalho Júnior nasceu em 1969, e seu primeiro contato com o barro foi aos seis anos de idade. Décio não pertence a família de figureiros, mas, morador do bairro Imaculada desde a infância, perto da Rua Imaculada, sempre manteve contato com figureiros.

Aos 11 anos ele iniciou seus estudos na Escola de Artes Maestro Fêgo Camargo, de Taubaté, onde frequentou durante dois anos o curso de arte para público infantil. Depois disso, conheceu Marcos Nogueira - neto da figureira Edwiges e amigo de seu irmão -, que lhe sugeriu entrar em contato com as irmãs figureiras da família Santos (Luiza, Edith e Cândida) para ser iniciado na arte dos figureiros, o que de fato aconteceu.

Décio destaca, na entrevista que deu à autora em 2009, que o aprendizado com as irmãs figureiras e principalmente com Luiza não era algo dirigido, dando-se mais pela convivência, orientação, observação e comparação que ele fazia entre sua produção e a delas.

Não era uma forma tão didática, dirigida. O que acontecia: eu chegava com meu produto lá e observava, lógico, o que elas estavam fazendo, e mostrava, e elas orientavam. Então, eu me lembro uma vez de ter feito uma galinha, pintei de azul e com pintinhas amarelas. E a galinha parecia um avião (risos). E era engraçado. Ou seja, para mim, aquilo estava certo, mas depois eu comparava com as delas e vi que ficava muito estranho, e eu tentava entender por que minha galinha não ficava tão bonita quanto as que elas faziam. Às vezes, elas me falavam: "Nossa, mas você precisava fazer mais redonda ou...". Mas elas não eram de falar muito. Até porque eu acho que elas queriam incentivar. (...) E elas não falavam muito, eram muito de observação, mas falavam o suficiente. Agora, havia o hábito na época de... nós participávamos muito de excursão. Muito, muito. Então, o convívio ali nas exposições acabava ajudando também. Então, foi uma coisa muito próxima, de muita proximidade. E elas tinham uma maneira muito sutil de cobrar caso você não fizesse, por exemplo, não arcasse com o compromisso. Por exemplo, ter marcado uma excursão e não ter ido. Elas cobravam de uma maneira muito peculiar. Elas cobravam a questão da responsabilidade. Então, havia além da técnica, uma certa postura. Até em re- 
Figura 2: Décio fazendo presépio

Foto da autora

lação à parte política, por exemplo, que é muito interessante. Chegava na época da eleição, a dona Luiza recebia - como recebe até hoje - todos os candidatos.

Todos. E ela sempre nos orientava sobre isso, de que o artista tem que ter essa capacidade. Mas ele não pode ter assim, ou pelo menos elas... Elas não assumiam uma atitude partidária. É uma atitude até política, porque na verdade é uma atitude política. Mas elas não tinham atitude partidária. Elas tinham total razão nisso. Então agora eu sigo o caminho delas até nisso. Então quando eu falo que ela nos orientou é uma coisa que você só vai assimilar anos, anos depois, tal a abrangência.

O aprendizado, portanto, não se limitava às técnicas, abrangendo uma questão de postura, de comportamento diante de todos os contextos que envolvem ou podem envolver a produção artesanal.

O fato de Décio ter iniciado seu aprendizado com os figureiros após ter frequentado uma escola de arte já foi fonte de conflitos. Sua produção, que de alguma maneira destoa da maioria dos figureiros, pois possui características escultórias, já foi motivo para questionar sua legitimidade enquanto figureiro, como ele esclareceu quando Ihe perguntei se sua produção diferenciada já havia gerado conflito dentro do grupo:

Olha, já. Você diz diferenciada entre tantas?! Já, já me chamaram... Uma vez, foi muito engraçado, falaram que eu não era figureiro. Eu falei: "Gente, mas peraí, se for a questão das patentes, eu aprendi com a dona Luiza". Foi muito engraçado que a minha bisavó foi quem levou... A dona Edith falando que eu era bisneto da Maria das Dores que levava barro. ${ }^{5}$ Eu acabei usando isso como argumento, não é?! Se a questão é a ancestralidade lá na ideia, eu comecei também a puxar as informações ligadas à minha família. E realmente, minha família é centenária no bairro também. Eu também tenho uma história, não é?! E o fato de ter feito Fêgo Camargo [escola de arte] realmente talvez tenha gerado uma discussão. Mas eu vi que 
Figura 3: Décio modelando pavão Foto da autora

a minha base estava ali com a dona Luiza. Meu norte ético era ali. Como ela nunca condenou... Para mim, a visão dela era a visão da matriarca. Como ela não condenou, eu não tinha dúvidas que os outros não teriam a autoridade de questionar. Então, ela era sempre a referência, meio que o limite. Se ela falasse alguma coisa, enfim... E como isso não aconteceu, eu não tinha assim, dor na consciência de ter continuado a fazer, como até hoje faço. Nenhum tipo de sentimento de culpa em relação a isso.

O relato de Décio traz à tona a questão da ancestralidade, tanto do parentesco como do território, algo que muitas vezes é usado como forma de legitimação dentro da produção figurativa. Por outro lado, há também o fato de o processo de aprendizado, associado à experiência do convívio com figureiros reconhecidos como legítimos, ser capaz de conferir legitimidade. Por último, há ainda o destaque dado ao papel de Luiza Santos que, além de surgir como figureira legítima, também é tomada em última instância como a principal legitimadora de outros figureiros.

Devido à especificidade da experiência de seu aprendizado no convívio direto e cotidiano com os figureiros, apesar de não pertencer a uma dessas famílias, morando no bairro Imaculada desde a infância e mantendo relações de vizinhança com todos os outros figureiros, Décio é classificado como figureiro tradicional.

Trata-se de uma categoria classificatória que considera em primeiro lugar não o parentesco consanguíneo, mas o parentesco por afinidade e conviência. Décio, desde a infância, pertence à coletividade do bairro Imaculada e, assim como os figureiros de família, aprendeu pelo convívio diário e de maneira não dirigida. Sua legitimidade enquanto figureiro passa pelo viés do próprio convívio e do compartilhamento de valores, pelo fato de se reconhecer e ser reconhecido como pertencente a essa coletividade (figuras 2 e 3 ). 


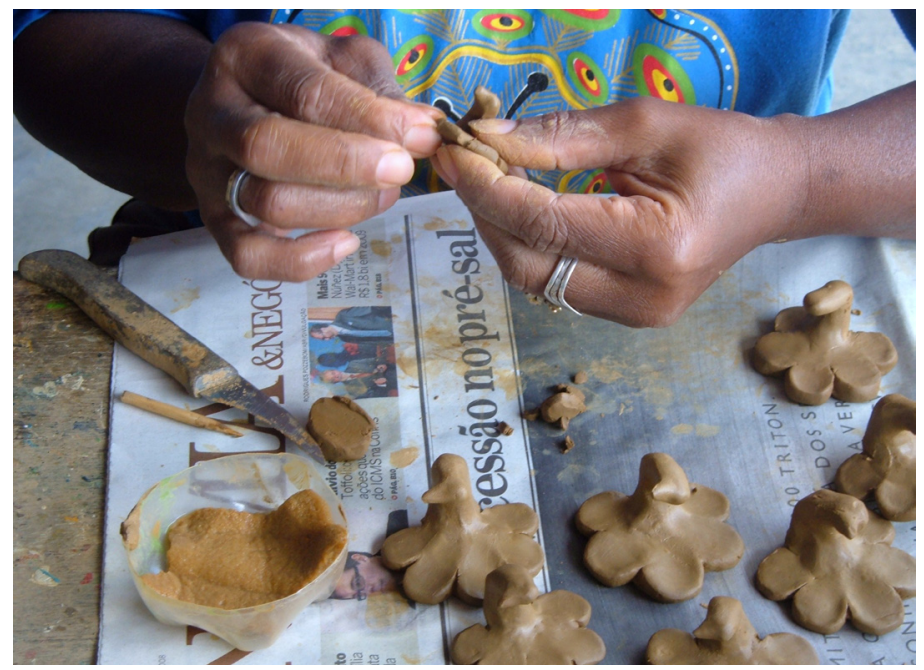

Figura 4: Elizabeth Machado modelando pavões Foto da autora

\section{Elizabeth Machado - uma nova geração}

A figureira Elizabeth Machado, que pertence à Casa do Figureiro há mais de dez anos, é classificada internamente na categoria dos novos figureiros, pois seu contato e aprendizado da arte figurativa se deu por meio dos cursos ministrados pela Associação.

Ao falar sobre seu ingresso na Casa do Figureiro, durante a entrevista que me concedeu em 2010, Elizabeth explicita que sua entrada foi mediada pela busca de qualificação profissional. Trabalhando como faxineira, estava em busca de cursos oferecido pela prefeitura que lhe proporcionassem algum tipo de qualificação. Conta que sua primeira visita à Casa do Figureiro aconteceu quase por acaso: ao ver a Casa pintada de azul e branco, que são as cores-padrão da prefeitura, entendeu que se tratava de um órgão municipal e assim tomou a iniciativa de perguntar se havia cursos profissionalizantes.

Eu entrei aqui, estava [passando por] perto; perguntei se tinha algum curso aqui. Eu nem via figura, eu só enxerguei ela [a figureira que estava atendendo]. Ela me tratou muito bem. Então, eu me senti assim à vontade, bem acolhida por ela. E ela falou assim: "Tem curso aqui sim. Vem aqui, só que está de férias, então você vem aqui que eles estão dando aula". Eu falei: "Paga?". Ela falou: “Não”. Eu falei: "Mas aula do quê?". Ela falou: "De argila, mexer com barrinho". Eu fiquei feliz. Era assim... antes do Natal. Ela falou: "Quando passar o Natal, em janeiro você vem". Aí, eu vim e estou até hoje aqui. (...) Hoje, graças a Deus, eu tenho um dinheiro assim, para eu levar o que falta dentro de casa, fazer até compra [para]dentro de 
Figura 5: Presépio

de Elizabeth Machado

Foto da autora

casa. Então, graças

a Deus eu consegui não sair, desistir.

Valéria: Seus dois filhos chegaram

a fazer o curso também?

Elizabeth: Fizeram. (...) Às vezes, quando eles estavam estudando, eles pediam dinheiro emprestado. Eu falava: "Te empresto, você me paga com figura". Foi sempre assim, sabe, para incentivar, para poder não perder a geração. Nós não somos da geração deles [dos figureiros de família], mas [podemos]continuar na nossa geração daqui para frente.

Ao mesmo tempo em que Elizabeth deixa claro sua motivação ao ingressar na Casa do Figureiro, também chama a atenção para a necessidade de dar continuidade à produção artesanal dentro da família. Aponta que as motivações de caráter econômico não excluem uma postura de perpetuação da prática artesanal, já que os novos figureiros de hoje serão os figureiros tradicionais de amanhã à medida que conseguirem repassar, dentro dos seus círculos de parentesco, as técnicas de modelagem das figuras.

Com o passar do tempo, essa percepção, que vê na produção figurativa um meio de profissionalização e inserção no mercado de trabalho, é muitas vezes relativizada, e os discursos dos novos sobre o lugar que eles ocupam na arte figurativa passam a focalizar também a importância e necessidade de conservar e manter uma prática artesanal secular como a dos figureiros de Taubaté (figuras 4 e 5$)$. 


\section{ÚLTIMAS CONSIDERAÇÕES}

O que parece explicitar-se no processo de ensino e aprendizagem entre os figureiros de Taubaté é que, com o passar do tempo, os ditos novos figureiros reelaboram o quadro de motivações que os leva a permanecer na arte figurativa, $\mathrm{e}$ passam a hierarquizar tais motivações da mesma maneira que os denominados figureiros tradicionais, sobrepondo-se a importância da produção figurativa enquanto parte da história individual, familiar e coletiva à sua importância comercial/econômica, o que não significa dizer que este último aspecto da produção artesanal não seja relevante para todos os figureiros.

A partir dessa ideia, podemos ter compreensão mais ampla do próprio processo de aprendizado entre os figureiros. Ao contrapormos o processo de aprendizado dos figureiros de família e tradicionais àquele dos novos, observamos algumas importantes diferenças. Em primeiro lugar, há o tempo necessário para que o aprendiz seja considerado um figureiro. Em segundo, há a forma de transmissão das técnicas de modelagem: para os tradicionais, a partir do convívio cotidiano no âmbito familiar e/ou de vizinhança; ${ }^{6}$ para os novos, a partir de um figureiro experiente que ensina durante dois anos. Há também as motivações que impulsionam o início do aprendizado: para os primeiros esse aprendizado se inicia de modo lúdico e, para os novos, visa desde logo à profissionalização. Apesar dessas diferenças, com o passar do tempo, os novos figureiros reelaboram os motivos de sua permanência na arte figurativa, e a motivação profissional, e mesmo econômica, passa a segundo plano; a continuidade de uma prática artesanal tradicional surge como principal motivação. Nesse aspecto, do ponto de vista da reconstrução e ressignificação de suas narrativas, novos e tradicionais se aproximam.

Esse raciocínio destaca os argumentos de que o processo de ensino/aprendizagem dos novos figureiros parece não se limitar ao período de dois anos, mas abranger todo o período que vai do primeiro contato com a arte figurativa até o momento em que o figureiro reconfigura as motivações para sua permanência na arte figurativa, aproximando-se ou se igualando àquelas expressas pelos tradicionais.

O tornar-se figureiro em Taubaté implica o compartilhamento de uma rede de significados e práticas intimamente ligadas à construção de uma imagem de totalidade local; trata-se do compartilhamento de um éthos e de uma visão de mundo adquiridos na prática social que envolve a arte figurativa. 


\section{REFERÊNCIAS BIBLIOGRÁFICAS}

ABREU, Maria Morgado. Aspectos do folclore em Taubaté. Taubaté: Prefeitura Municipal de Taubaté. Série Taubateana, n. 7. 1980.

BARROS, Myriam Lins de. Memória e família. Estudos Históricos, Rio de Janeiro, v. 2, n. 3, 1989.

CAVALCANTI, Maria Laura Viveiros de Castro; VILHENA, Luís Rodolfo. Traçando fronteiras: Florestan Fernandes e a marginalização do folclore. Estudos Históricos, Rio de Janeiro, v. 3, n. 5, 1990.

DURKHEIM, Émile; MAUSS, Marcel. Algumas formas primitivas de classificação: contribuição para o estudo das representações coletivas. In: MAUSS, Marcel. Ensaios de sociologia. São Paulo: Editora Perspectiva, 2001.

FLORES, Noemi. Uma rua chamada Imaculada. Taubaté: Mistau (Museu da Imagem e do Som de Taubaté), 1987.

HALBWACHS, Maurice. A memória coletiva. São Paulo: Vértice, Editora Revista dos Tribunais, 1990.

LIMA, Rossini Tavares. Abecê do folclore. São Paulo: Ricordi, 1972.

MACHADO, Alessandra. As figureiras da Rua Imaculada Conceição de Taubaté. Taubaté: Prefeitura Municipal de Taubaté. Série Taubateana, n. 21, 2003.

OLIVEIRA, Marcelo P. de. O galinho do céu: os saberes das figureiras de Taubaté. 2007. Tese (Doutorado em Multimeios) - Curso de Pós-Graduação em Multimeios, Universidade Estadual de Campinas, Campinas, 2007.

PEREIRA, Carlos José da Costa. A cerâmica popular da Bahia. Salvador: Publicações da Universidade da Bahia, 1957.

REIS, Daniel. Visite o Brasil: classificações, experimentações e exibições no Museu Rossini Tavares de Lima. In: CAVALCANTI, Maria Laura Vieiros de Castro; GONÇALVES, Renata S. (Org.). Seminário Circuitos da Cultura Popular. Rio de Janeiro: UFRJ/IFCS, 2010.

SOTO, Maria Cristina M. Pobreza e conflito: Taubaté 1860-1935. São Paulo: Annablume, 2001.

\section{NOTAS}

1 Por categoria nativa de classificação estou tomando os termos de origem social compartilhados pelo grupo para ordenar, isto é, classificar seres, acontecimentos, lugares etc., a partir de noções hierarquizadas entre as próprias categorias e que tem como finalidade "fazer compreender, tornar inteligíveis as relações existentes entre os seres" (DURKHEIM, MAUSS, 2001, p. 450-451).

2 Movimento Folclórico era a expressão utilizada pelos próprios integrantes para designar o conjunto de iniciativas que visavam a "salvaguarda, estudo e pesquisa do folclore nacional" (III Semana Nacional do Folclore, 1950 apud CAVALCANTI, VILHENA, 1990, p. 76). 
30 Museu de Artes e Técnicas Populares de São Paulo, que também era conhecido como 'o museu do Rossini', passa a receber oficialmente o nome de seu fundador a partir de sua morte, em 1987 (REIS, 2010, p. 3).

4 Os feitos de 32, a que se refere Camargo, dizem respeito à denominada Revolução Constitucionalista de 1932, para a qual Taubaté enviou voluntários que formaram o "Batalhão Jaques Felix", ou se juntaram ao "Batalhão Mantiqueira", ou ao "Batalhão Arquidiocesano", todos acantonados em Taubaté (sото, 2001, p. 242). Já os feitos de 45 dizem respeito ao envio de jovens taubateanos para integrar a Força Expedicionária Brasileira (FEB), que esteve presente nos campos de batalha da Itália, durante a Segunda Guerra Mundial (19371945).

5 A figureira Luiza, em entrevista, diz que a bisavó de Décio, Maria das Dores, vendia barro para os artesãos da Rua Imaculada. Foi dela, aliás, que Narciso, pai de Luiza, comprou a primeira lata de barro para que ela e sua irmã, Edith, aprendessem a modelar figuras.

6 Vale destacar que todos os figureiros de família são também figureiros tradicionais, embora nem todos os figureiros tradicionais sejam figureiros de família.

Valéria Aquino é graduada em ciências sociais (UFG), mestre em sociologia, com concentração em antropologia, doutora em antropologia cultural (IFCS/UFRJ), e professora do lart/Uerj.

Recebido em: 19/06/2012

Aceito em: 19/01/2013 